\title{
EchoGéo
}

55 | 2021

Espace et parentalité

\section{Space and parenthood}

Introduction

Sophie Moreau and Félicie Roux

\section{(2) OpenEdition}

Journals

Electronic version

URL: https://journals.openedition.org/echogeo/21573

DOI: 10.4000/echogeo.21573

ISSN: 1963-1197

\section{Publisher}

Pôle de recherche pour l'organisation et la diffusion de l'information géographique (CNRS UMR 8586)

Electronic reference

Sophie Moreau and Félicie Roux, "Space and parenthood", EchoGéo [Online], 55 | 2021, Online since 01 June 2021, connection on 11 August 2021. URL: http://journals.openedition.org/echogeo/21573 ; DOI: https://doi.org/10.4000/echogeo.21573

This text was automatically generated on 11 August 2021.

EchoGéo est mis à disposition selon les termes de la licence Creative Commons Attribution - Pas d'Utilisation Commerciale - Pas de Modification 4.0 International (CC BY-NC-ND) 


\title{
Space and parenthood
}

\author{
Introduction
}

\section{Sophie Moreau and Félicie Roux}

1 This issue explores an almost overlooked area of geography: the spaces of parenthood. While the analysis of kinship relations is a classic field of anthropology, parenthood only recently became a common term in the media and a category for public policies (Chauvière 2008; collective 2016). In particular, health and education institutions have been seeking to frame this notion, increasingly disseminating the injunction to be a 'good parent' (Martin 2014). Unlike geography, the sociology of the family and that of education have already embraced this theme. However, French geographers have so far shown little interest in parents as a social group, defined by its specific relations to children. So far, they have only been approached through the geographies of childhood or schools, but as peripheral actors (Authier and Lehman Frisch 2012; Lehman Frish and Vivet 2012).

2 We have chosen to make parents the main protagonists of this issue. To define this social group, we worked from the definition of parenthood understood as a work of social production and reproduction whose objective is to raise children, involving both material and symbolic dimensions (Dechaux 2009).

Contributions to this volume deliver insights into a range of tasks associated with parenting: looking after the children's safety and health, washing them, laundering their clothes, feeding them, watching over them, walking them in strollers, taking them to school or to the Conservatoire (dance or music classes), attending their dance performances, taking them to the Opera, teaching them, entertaining them, giving them access to spaces of sociability and friendships, imparting moral values, guiding them onto an upward social trajectory, engaging with the local community... We worked from the hypothesis that parenting practices are constructed in and through space, in the sense that they are shaped by the spatial arrangements in which they occur and, conversely, that parents are also actors of socio-spatial mutations. Through the contributions compiled in this issue, we will see that parenthood involves spatial practices that can be examined at different scales (housing, neighborhood, city, world) and in different fields (housing, leisure, education, travel, community engagement), 
shaped according to differentiated trajectories and social identities. But first of all, who are the parents?

\section{Not just a family affair?}

Almost all contributions study French society and, quite unexpectedly, few of them consider parents in the family context. The families' make-up is of little interest to our authors, whether these are nuclear or single-parent families, families with same-sex or different-sex parents, broken or recomposed families. The conjugal family, consisting of a couple and their children, is rather underrepresented, except in Anne Gaugue's article on globe-trotting parents whose families both open up to the world and withdraw into themselves in the hull of their boat, especially in bad weather. The couple of young Gipsy parents described by David Giband, pushing their young children in strollers in the streets of the Saint-Jacques district of Perpignan, are a rather new social figure in Gypsy society.

The articles in this issue represent parenthood as organized between two polar opposites: the individual on the one hand, and the collective on the other - which may reflect the decline of the traditional conjugal family model in France, or the (re)assertion of larger collective parenthood structures that have in fact always been there but had so far lacked social recognition in France.

These authors examine constructions of parenthood within the context of larger structures. The parallel between David Giband's article on Gypsy parenting and Chloé Salembier and Gérald Ledent's text on a participatory housing community in Brussels is enlightening. Both authors are interested in collective parenthood, in the first case in the context of the Gypsy community's extended family (including uncles, aunts, grandparents, cousins...), all of whom contribute to parenting tasks, and in the second case in the context of a cohousing community in Brussels, where families can share the material tasks associated with parenthood: looking after and supervising the children, feeding them, bathing them, etc. For the Gypsies presented by David Giband, this traditional form of collective parenting was once the norm, but it is now being challenged by young couples who are trying, with varying degrees of success, to assert a form of couple-based parenting in line with 'French' social norms. On the other hand, for the inhabitants of the cohousing community in Brussels, collective parenthood is seen as an emerging alternative that doesn't challenge the couple's status as co-parents but complements and improves it.

7 In all these contributions, parenthood appears mostly as a matter of individuals, captured through their engagements with diverse institutions (the school, the Conservatoire, the extended family, the couple), injunctions (to be a good parent, to provide a good education, to work), dynamics (upward or downward social mobility), and discriminations (racial, social).

8 Parenthood is mostly approached from a female perspective. Is this due to a methodological bias, as the authors mainly worked from individual interviews? None of them appear to have deliberately chosen to work mainly with mothers, but no article addresses fathers' parenting as its main object. And yet, these studies reflect a very gendered perspective on parenthood. While fathers are not absent from the interviews, mothers have more say in expressing their projects, their strategies, their concerns. Women talk more from a personal than a couple-centric perspective. In Brussels, they 
are the ones who emphasize the advantages of co-housing in terms of parenting, including the relief in terms of everyday domestic work. In Perpignan's Gipsy families, couple-centric parenting practices are endorsed by younger mothers much more than by fathers, who are ridiculed when they are seen in public to take part in childcare. The mothers are also the ones who queue for hours to sign up their daughters for classes at the Conservatoires in the eastern suburbs of Paris. They are the ones who drive them to their classes and cry at their end-of-year shows - or on the contrary, who do not attend because they feel that they do not belong. Mothers are also involved in militant networks in Seine-Saint-Denis (suburb of Paris), including racialized mothers and mothers from immigrant backgrounds, as if parenthood gave them access to a window of social visibility, enabling them to take part in political action.

9 By focusing on parenting as a set of practices associated with social reproduction, rather than as biological or authority relations that also define kinship, these articles redefine the social boundaries of parenthood. Contributors are mainly interested in the variations of parenthood according to the parents' social affiliations and trajectories in terms of class, ethnic identity, or migratory and residential pathways. These articles describe people including very young Gypsy parents in the disadvantaged area of SaintJacques in Perpignan, parents from the middle to upper classes with a high level of education who sail the world in pleasure boats with their children, etc.: in other words, parents from working-class, middle-class and upper-class areas in major European cities (Brussels, Paris, Lyon) and their suburbs, whose diverse social mosaic is the product of immigration, settlement and gentrification.

\section{Parenthood and spatial dispositifs}

10 The notion of spatial dispositif, defined as 'a system that renders power and norms concrete and effective but discrete, by materially anchoring them in a specific place' (Estebanez 2011), is used by Natacha Gourland to refer to the network and internal spatial organization of Conservatoires in the Paris region. This notion informs the analysis of parenting, well beyond the sole case of these institutions. Indeed, the different texts show how parenthood is shaped by diverse norms and power constraints that materialize into specific spatial configurations.

11 The first of these dispositifs is housing, as illustrated by two apparently very different examples in Anne Gaugue's and in Chloé Salembier and Gérald Ledent's articles. A cohousing community is a very precisely organized space (a layout plan is presented by the authors, who are trained architects), accommodating on the one hand private spaces for nuclear families, and on the other hand shared recreational and productive spaces (gardens, patios, passages, sometimes kitchens and laundry rooms). Its symbolic virtue resides in the fact that it welcomes collectives. On the contrary, the pleasure boat is described as the family's outer shell. It is a space that symbolizes their freedom to make their own choices and live their own life, which is presented to the children as an educational model; but it is also a material space, an intimate cocoon where the family can retreat from the storms and from the alien world encountered in the harbors. It is also perceived during the long crossings as a sometimes oppressive enclosed space, and as a fragile and unsafe space, especially for young children, which can be a source of anxiety when the family is out at sea. The marina functions as a second, temporary home offering more safety and interaction with others, and 
providing an opportunity for children and parents to build their autonomy, especially through school and through the friendships that are formed there.

Natacha Gourland's article provides another example of a study of space on a very fine scale. Her article explores the Conservatoires: the entrance halls where the parents (especially mothers) sit while they wait for their children, the dance studios lined with ballet bars and mirrors... These schools function as spaces for the performance and construction of parenthood in the context of institutionalized power relations. For the parents, being at the Conservatoire manifests the fact of being a good parent by participating in an elitist social project that places demands on their time (to drive the children to their classes and wait for them). For the teachers, the dance studio is the place where the children's bodies are shaped. The waiting hall is also the place where the parents meet the institution, and where the latter disseminates the standards of this elitist culture that encourages children to go see The Nutcracker at the Paris Opera rather than watch Barbie cartoons.

The next scale up is that of the neighborhood, considered as a place of production and reproduction of behavioral norms in public space. David Giband shows very well how the Saint-Jaques neighborhood is a space of assertion and construction of the Gypsy identity through the exercise of extended parenthood: the squares and crossroads where the Companya (the elders) keep watch, scolding those who do not behave in line with the Gypsy norm; the alleys and doorsteps where children play under the gaze of their uncles, aunts, grandmothers and grandfathers. This space is also where some young couples assert their alternative parenting practices by pushing their children in strollers and walking them to school, even though schooling is scorned by the elders.

space can become a framework and a means for the consolidation or re-negotiation of social relations of domination. For example, the spaces of the neighborhood or collaborative housing unit bring into question the re-arrangement of gender relations or relations to gender, when private and (semi-)public spaces collide. Chloé Salembier and Gérald Ledent both analyze the reconfigurations of the gendered dimension of parenting. Although cohousing makes it possible 'to better reconcile people's different productive, reproductive and social/community-related roles', certain inequalities do nonetheless persist and are apparent in the gendered distribution of roles within the couple.

Social relations of race are analyzed by David Giband through the notion of 'territorial ethnicity', coined by Françoise Lorcerie (2009) to delineate the boundaries of spaces and social groups. Natacha Gourland examines the cultural illegitimacy of mothers who wear a Muslim veil and are subjected to Islamophobic judgments by Conservatoire teachers 'in a discipline that remains closely associated with standards of whiteness'. Félicie Roux, finally, shows how the experience of racialization shapes relations to space, leading to the internalization of unequal opportunities. This experience generates processes of collective identification, thus contributing to the parents' politicization.

\section{The spatial dimension of social reproduction}

Places can also be seen as a vector of social reproduction, providing a grid within which parents develop individual strategies, in particular in terms of education. The impact of parenting on space - whether on a neighborhood or a global scale -, on the 
reproduction of groups and social positions, or on upward social mobility strategies can be analyzed from the perspective of the (re)production of inequalities.

17 Cities, neighborhoods or local authorities function as symbolic reference points for the parents. This can be observed through the processes of identification associated with the family's belonging to a given local community, as shown by the analysis of Gypsy parenthood (D. Giband), or in that of parental disputes (F. Roux). Local context conditions parental strategies in terms of school choices (M. Guinepain) or education and leisure activities (N. Gourland).

Through their residential choices and mobility, parents produce spatial and social networks that illustrate their efforts at emancipating themselves or climbing the social ladder. David Giband, for instance, describes how the parents' reproduction of norms or attempts to subvert them are played out in the public space of the neighborhood, and through the mobilities that allow them to get out. Emancipation from the Gypsy norm is achieved through outward mobilities, for example, by visiting shopping centers on the outskirts of Perpignan. Some parents make their residential choices based on the location of the Conservatoires (N. Gourland). On a global scale, globe-trotting parents build a network to give their children access to an international culture. They organize the location and duration of their stopovers according to their educational project (schooling), to the friendships formed by the children, and to the seasons. In ports, they meet other globe-trotting parents who chose the same places for the same reasons (A. Gaugue).

19 Parenting practices thus bring into play a 'sense of placement' (Poupeau and François, 2009), examined here through its spatial dimension. The aim for parents is to distinguish themselves and their children in the local space or to climb the social ladder. This is apparent in Maxime Guinepain's article, documenting how parents 'choose' their children's schools in Lyon according to certain 'representations of the city'; and in Natacha Gourland's contribution, where children's access to the Conservatoire is based on distinction strategies in working-class communities in the Paris suburbs.

In these strategies of social (re)production, the places' characteristics add up to the parents' social determinants. Félicie Roux investigates how school is at the heart of strategies of social climbing or reproduction. In the case she studies, reproduction and distinction intersect with politicization, whose social determinants can be found in the biographical construction of individuals' relation to space, school and politics. For instance, in Seine-Saint-Denis, the parents' political commitments are not so much determined by the social and spatial characteristics of their neighborhoods, but rather by the encounter between these neighborhoods and the parents' social, migratory and residential trajectories. Natacha Gourland and Maxime Guinepain show how access to the Conservatoire or school choices are shaped by inequalities of capital between parents as well as by socially differentiated relations to local space.

\section{Conclusion}

21 The articles compiled here highlight how parents' spatial practices raise questions on social reproduction - of one's position or belonging to a group - and on the possibility of social change. These practices are shaped by spatial constraints, but they also produce networks of affiliation and contribute to the perpetuation or production of 
socio-spatial inequalities. By moving or, on the contrary, by settling, parents contribute to the reproduction of social inequalities of class, gender and race. However, their spatial practices also contribute to recomposing and attempting to subvert certain norms, particularly gendered ones, and to challenging inequalities through parental politicization. Space provides a frame of reference in relation to which parents position themselves: it can provide a setting for the re-arrangement of gender relations, impart a stigma from which parents seek to distance themselves, or act as a criterion of choice in educational strategies. Space is also a frame of reference that can contribute to the construction of collective identities (through a process of reverse stigmatization), bringing together heterogeneous social groups who collaborate to protest against the public authorities.

INDEX

Subjects: Sur le Champ - Sur le Terrain 